JEL classification: G21, N23

УДК 336.7(571.5)(091)

DOI 10.17150/2308-2488.2021.22(1).121-139

Е.В. Плотникова

Иркутский государственный университет, г. Иркутск, Российская Федерация

ПОЛИТИКА ПРАВЛЕНИЯ СИБИРСКОГО ТОРГОВОГО БАНКА В ОТНОШЕНИИ РЕГИОНАЛЬНЫК ПОДРАЗДЕЛЕНИЙ: СЛУЧАЙ ИРКУТСКОГО ОТДЕЛЕНИЯ, 1873-1920 ГГ.

Аннотация. В статье на примере Иркутского отделения рассматривается политика Сибирского торгового банка, проводившаяся его правлением в отношении региональных подразделений в 1873-1920 гг. Данная политика осуществлялась посредством направления отделениям циркуляров и инструкций, регулировавших их деятельность в соответствии с общей концепцией развития банка. Регламентировавшие деятельность региональных подразделений банка документы хранятся, преимущественно, в исторических архивах г. Иркутска и г. Санкт-Петербурга. Некоторые из циркуляров носят общий характер, другие относятся непосредственно к иркутскому отделению. Анализ документальных материалов позволил установить ключевые направления, а также характер политики банка в отношении местных подразделений. Политика банка основывалась на тщательном анализе экономики региона, охваченного их деятельностью, для чего руководством банка изучались все местные периодические издания, направляемые отделениями в адрес правления. Особое внимание уделено политике банка в отношении учетных комитетов отделений, характеризующейся осторожностью и, в некоторой степени, недоверием. Руководству Сибирского торгового банка была не чужда социальная политика в отношении своих служащих, которым в отдельных случаях предоставлялись жилье и различные денежные пособия. В целом, политику 
руководства банка, проводимую в отношении региональных подразделений можно квалифицировать как прагматичную и сдержанную, но не лишенную при этом социальной направленности.

Киючевые слова. Сибирский торговый банк, Иркутская губерния, региональные отделения, банковская политика, учетный комитет.

Информация о статъе. Дата поступления 12 января 2021 г.; дата принятия к печати 18 февраля 2021 г.; дата онлайн-размещения 3 марта 2021 г.

E.V. Plotnikova Irkutsk State University, Irkutsk, the Russian Federation

\title{
THE POLICY OF MANAGEMENT BOARD AT SIBERIAN MERCHANT BANK TOWARD REGIONAL BRANCHES: THE CASE OF THE IRKUTSK BRANCH BETWEEN 1873 AND 1920
}

\begin{abstract}
The article focuses on the policy conducted by the Management Board of Siberian Merchant Bank in reference to its regional branches from 1873 to 1920 using the example of the Irkutsk Branch. The policy included circulars and instructions that were sent to the branches and were supposed to regulate their activity in order to comply with the Bank's general development strategy. The documents, regulating the activity of regional branches, are kept mainly in historical archives of Irkutsk and St. Petersburg. Some of the circulars are general in nature, some of them relate to the Irkutsk Branch and its activity. The research reviewed the documentary materials, defining the key directions and peculiarities of the Bank's policy concerning to the regional branches. The Bank's policy was based on the detailed analysis of the economic situation in the region under the coverage of its activity. The Management Board thoroughly studied all the local periodicals, which the regional branches sent to them. A special focus in the article is given to the Bank's policy toward regional Accounting Committees,


which was cautious and rather distrustful. It should be mentioned that social policy toward its employees was not alien to the Management Board of Siberian Merchant Bank. It could include provision of housing and various financial incentives. As a conclusion, in general the Bank's policy toward regional branches can be described as pragmatic, moderate, but not excluding its socially-oriented approach.

Keywords. Siberian Merchant Bank, the Irkutsk Governorate, regional branches, the Bank's policy, Accounting Committee

Article info. Received January 12, 2021; accepted Fabruary 18, 2021; available online March 3, 2021.

Управленческая политика является одним из ключевых элементов функционирования кредитных институтов как в современной, так и в дореволюционной России. От ее специфики зависят направления деятельности кредитного учреждения, его ориентация на определенные сегменты рынка, приверженность к рискованным операциям, основные подходы в подборе кадров и предоставлении социальных гарантий своим сотрудникам и т.Д. В этом отношении анализ банковской политики представляет научный интерес как для формирования целостной картины эволюции банковской сферы дореволюционной России, так и для осмысления ее влияния на развитие конкретных кредитных институтов.

Различным аспектам организации, функционирования и развития акционерных коммерческих банков России конца XIX - начала XX в. посвящены исследования И.Ф. Гиндина, Г.Х. Рабиновича, Б.В. Ананьича, Ю.А. Петрова, В.И. Бовыкина, С.А. Саломатиной [1-5]. Вопросы формирования благоприятной внутренней и внешней среды функционирования банков в Иркутской губернии XIX - начала XX в. нашли отражение на страницах работ В.П. Шахерова и Н.И. Гавриловой, затрагивающих, в основном, деятельность ключевого звена кредитно-финансовой системы региона - Ир2021. T. 22, № 1. С. 121-139 
кутского отделения Государственного банка [6-8]. Настоящая публикация освещает политику, проводившуюся руководством Сибирского торгового банка в отношении региональных подразделений и, прежде всего, его Иркутского отделения.

Сибирский Торговый банк был учрежден в г. Екатеринбурге на основании устава, утвержденного 5 июля 1872 г. ${ }^{1}$ Банк являлся акционерным, среди его учредителей были такие видные государственные деятели как П.А. Шувалов и П.П. Дурново, известный купец и финансист Г.О. Гинцбург, промышленник и общественный деятель М.А. Нуров, военный и наследственный золотопромышленник В.И. Асташев, банкир и крупный золотопромышленник Н.Д. Бенардаки, крупный финансист и общественный деятель Л.М. Розенталь.

В г. Иркутске отделение Сибирского торгового банка открылось 25 февраля 1873 г. По случаю открытия отделения собралось большое количество гостей, в присутствии которых был совершен молебен. Впоследствии был дан званый обед, который удостоили своим присутствием генерал-губернатор Восточной Сибири Николай Петрович Синельников и другие высокопоставленные лица. Иркутская общественность, в лице представителей прессы, пожелала новоявленному кредитному учреждению успеха и выразила надежду, что его появление оживит в крае торговую и промышленную деятельность и позволит дать большее движение капиталам². Банковское отделение располагалось на углу Трапезниковской улицы и Базарной площади, в доме Баснина.

Отделение осуществляло свою деятельность в соответствии с циркулярами, регулярно высылаемыми

${ }^{1}$ Устав Сибирского Торгового банка от 5 июля 1872 г. / / Полное собрание законов Российской империи. Собрание второе. T. XLVII. Отделение 2. C. 61. URL: https:/ / runivers.ru/bookreader/ book9964/\#page/62/mode/1up (дата обращения: 18.12.2020).

${ }^{2}$ Иркутские губернские ведомости. 1873. 10 марта. С. 3. 
правлением, которые регулировали как общие, так и частные вопросы банковского производства. Вся материальная ответственность по приему и выдаче документов лежала на заведующем соответствующим отделом, кассире, принявшем или выдавшем ценность, а также на сотруднике, осуществлявшем за ними контроль ${ }^{3}$.

Правление банка старалось следить за экономическим положением районов, в которых действовали отделения. С этой целью оно рекомендовало руководству на местах осуществлять подписку на все региональные периодические издания ${ }^{4}$ К Кроме того, правление настаивало, чтобы в отделениях кроме управляющего и бухгалтера имелись еще как минимум дватри сотрудника, близко знакомых с экономическими условиями жизни в Сибири и проживавших здесь долгое время. Для этого отделениям было дано указание вести планомерную работу по подготовке будущих кадров. В частности, подающих надежды служащих рекомендовалось готовить на должность бухгалтера с перспективой работы в качестве управляющего. При приеме нового работника в отделение на более или менее серьезное вакантное место учитывался как его нравственный облик, так и способность в дальнейшем занять, по крайней мере, место бухгалтера. Также учитывалась готовность кандидата, в случае необходимости, к переезду для работы в другом отделении банка в регионе 5 . Правление просило отделения высылать характеристики личного состава учреждения для того, чтобы при освобождении разного рода вакансий иметь возможность замещения должностей

Хотя бы один из артельщиков отделения всегда должен был проживать в помещении банка. Каждый

${ }^{3}$ Российский государственный исторический архив (РГИА). Ф. 638. Оп. 1. Д. 3. Л. 1.

${ }^{4}$ Там же. Л. 27.

${ }^{5}$ Там же. Л. 28.

${ }^{6}$ Там же. Л. 111. 
артельщик, живший при банке, пользовался квартирой бесплатно. При этом артельщики, не имевшие возможности устройства при банке в виду недостатка свободных квартир, не получали от него квартирного пособия, так как по договору банк не обязан был снабжать их бесплатным жильем. По распоряжению правления это правило не подлежало никаким исключениям, хотя и не лишало служащих квартирного пособия, в случае, если они уже пользовались таковым. Сотрудники, которые получали пособие на аренду жилья до 1898 г. продолжали получать его и в дальнейшем ${ }^{7}$. При увольнении служащим полагалось выходное пособие при условии, что они проработали в отделении не менее года и не имели проступков против интересов банка ${ }^{8}$.

В 1885 г. была выпущена внутренняя инструкция относительно деятельности учетных комитетов отделений. В уточнение к ней был издан циркуляр, в соответствии с которым управляющие на местах обязывались дважды в год после проведения Ирбитской и Нижегородской ярмарок доставлять правлению пересмотренный с помощью учетного комитета кредитный список лиц и фирм, имевших предпосылки работы с отделением. Список включал имущественное положение лиц, характер деловой активности, размер торговых оборотов, информацию по кредитованию в сторонних учреждениях. В него входили сведения об общественной жизни клиентов, их возрастные характеристики, наличие заместителей, а также некоторые индивидуальные особенности, такие как энергичность, распорядительность, способность продолжать ведение дел и т.д.

В отношении операции учета векселей основная ответственность возлагалась на управляющего отделением. Последний до рассмотрения векселей учетным

${ }^{7}$ РГИА. Ф. 638. Оп. 1. Д. 3. Л. 30.

${ }^{8}$ Там же. Л. 53. 
комитетом обязан был лично собирать все сведения относительно каждого лица являвшегося предъявителем векселя, векселедателем, бланконадписателем или поручителем, чтобы выражать собственное суждение по каждой учетной операции. Собранные сведения не подлежали разглашению учетному комитету и служили для формирования мнения самого управляющего. Также не подлежала огласке комитету и информация из утвержденного правлением кредитного списка. Учетный комитет имел лишь совещательную функцию при отделении банка, и управляющий имел право отклонять векселя, как уже прошедшие одобрение комитета, так и не дошедшие до его рассмотрения. В случае, когда кто-либо из членов учетного комитета настаивал на приеме к учету векселя, вопреки мнению управляющего, ситуация выносилась на суд правления, которое выносило окончательный вердикт. Правление неоднократно подчеркивало, что члены учетного комитета являются лишь только советниками, снабжающими управляющих отделениями «всякого рода полезными сведениями» о кредитоспособности лиц, и вся ответственность за неосторожные действия и возможные потери банка лежит всецело на руководстве отделения. Отделения банка проводили взвешенную политику и искали пути сокращения банковского риска. Так, например, оно старалось предоставлять каждому из городских нотариусов какую-нибудь работу, в частности, связанную с протестом векселей, для того чтобы в свою очередь получать от них информацию об опротестованных векселях других банков, таким образом исключая рискованные операции в своем 9 .

В Сибирском торговом банке существовал ряд ограничений относительно кредитов для золотопромышленников. Иркутское отделение не могло самостоятельно принимать решения о выдаче золото-

${ }^{9}$ РГИА. Ф. 638. Оп. 1. Д. 3. Л. 19-20. 
промышленных ссуд. Каждое золотопромышленное предприятие, обратившееся в банк за ссудой, проходило процедуру одобрения со стороны его правления на предмет получения кредита. При этом правление могло устанавливать индивидуальные условия кредитования, отличные от тех, которые действовали в отношении других клиентов банка. Золотопромышленные кредиты открывались лишь промышленникам или предприятиям, уже функционировавшим на рынке до открытия кредита и обнаружившим свою жизнестойкость и кредитоспособность. При определении размера и условий кредитования принимались в расчет данные балансовой отчетности, а также результативность деятельности предприятия за предшествующие годы. Банк рассматривал смету добычи золота на предстоящую кампанию, а также кредитоспособность как предприятия в целом, так и всех его собственников или пайщиков в отдельности.

Кредиты золотопромышленникам выдавались, по возможности, с условием, что все добытое за текущую золотодобывающую кампанию золото, будет сдаваться в золотосплавочную лабораторию Сибирского торгового банка, при этом банку давалось право погашать долг предприятия из расчетов за сданное золото. Если предприятие-заемщик нарушало договорные обязательства и реализовывало золото в обход Сибирского торгового банка, оно уплачивало штрафные санкции в размере 10 \% от всей суммы добытого за минувшую кампанию золота даже при условии, что долг по кредиту был полностью покрыт. В случае если предприятие одновременно являлось заемщиком Государственного банка и уже подписало обязательство о сдаче добываемого золота в казенную золотосплавочную лабораторию, оно должно было предоставить удостоверение, выданное Государственным банком о том, что из вырученных за золото сумм последний будет выплачивать Сибирскому торговому банку опре- 
деленные денежные суммы. Выплата по кредиту устанавливалась не единым платежом в конце расчетного периода, а с частичным погашением в течение всего срока кредитования. До полного возврата заемных средств, отделение не имело права открывать предприятию новый кредит. Наиболее приемлемой формой кредитования золотопромышленников в банке считались ссуды в форме учета векселей или ссуды до востребования под залог векселей с двумя или более подписями. Соло-векселя, т.е. веселя с одной подписью, в случае с кредитованием золотопромышленности не принимались ${ }^{10}$.

В отличие от кредитования золотопромышленников, при котором правление разрешало выдачу средств под залог векселей, в остальных случаях данная операция не приветствовалась. Более предпочтительной являлась для отделений учетная вексельная операция. Это обстоятельство обусловливалось тем, что специальный счет под векселя предоставлял гораздо меныше выгод банку, чем учет векселей, в виду того, что проценты по специальному счету взимались по истечении четвертей года, а по учету векселей вперед. Кроме того, по специальному счету допускалось погашение долга частями и в любые сроки, соответственно чему уменьшалось и начисление процентов по кредиту. Еще одним обстоятельством служило то, что кредит под залог векселей имел тенденцию к постоянной задолженности и труднее поддавался ликвидации на практике. По этой причине правление допускало открытие кредита под залог векселей лишь в форме исключения, в том случае, если, например, клиент был очень интересен банку и проходил бы в отделении по другим операциям, в частности, хранил все свои средства или их большую часть на депозитных счетах. Но даже в этом случае, не все векселя при-

${ }^{10}$ Государственный архив Иркутской области (ГАИО). Ф. 155. Оп. 1. Д. 17. Л. 82-84 об. 
нимались в обеспечение по кредиту, а лишь те из них, которые имели торговое происхождение и, по возможности, имели краткосрочный характер ${ }^{11}$.

Что касается финансовых векселей, не проходивших по торговым сделкам, а служивших простым обязательством денежного погашения, банк крайне неохотно принимал их в обеспечение по кредиту. В исключительных случаях, если дело касалось солидных клиентов, в которых отделение было заинтересовано, мог быть рассмотрен вопрос о выдаче такого рода кредита, но лишь в качестве операции учета и только по согласованию с правлением.

Также нежелательной являлась операция по приему на хранение ценностей и процентных бумаг. Этот вид кредитных операций правление считало бесполезным для банка, не приносящим достаточной прибыли и возлагавшим на банк лишнюю ответственность. В этой связи данный вид операций был запрещен отделениям банка внутренним циркуляром и допускался лишь как сопутствующий в исключительных случая ${ }^{12}$.

В своей деятельности Сибирский торговый банк исходил из принципа приоритета краткосрочных банковских операций перед долгосрочными. Это требование было не только прописано в уставе банка, но и отражало всю его финансовую политику в целом. Большая часть денежных ресурсов, помещаемых банком в активные (преимущественно, ссудные) операции, формировалась из капиталов, размещаемых вкладчиками. В этой связи банк должен был всегда считаться с перспективой необходимости освободить свои средства в виду возможности предъявления требований со стороны своих вкладчиков. Поэтому правление банка настаивало на том, чтобы вексельный портфель отделения обладал эластичностью с возможностью

${ }^{11}$ ГАИО. Ф. 155. Оп. 1. Д. 17. Л. 85.

${ }^{12}$ РГИА. Ф. 638. Оп. 1. Д. 3. Л. 13. 
его сокращения и высвобождения денежных средств в любое время по мере необходимости. Это условие требовало, чтобы сроки возврата денежных средств по векселям были небольшими. По этой же причине банк стремился выдавать краткосрочные ссуды под залог ликвидных товаров и неохотно принимал недвижимое имущество в качестве обеспечения по кредиту, ввиду того, что в случае несостоятельности заемщика его реализация могла приобрести затяжной характер. Другим обстоятельством, объяснявшим нежелание банка принимать в залог недвижимость, было опасение, что в банк получат доступ лица не имеющие ничего общего с коммерческой деятельностью, либо предприниматели, которые все свои кредитные ресурсы целиком вложат в основание учреждаемых ими предприятий, не оставив себе никакой «подушки безопасности» на случай неудачи их начинаний ${ }^{13}$.

Среди лиц, искавших кредитной поддержки Иркутского отделения банка, числились представители купеческого сословия, мещане, а также крестьяне, занимавшиеся предпринимательской деятельностью. Кроме частных лиц к услугам банка прибегали различные компании, представлявшие собой товарищества: «Филатов и Зицерман», «Иркутское лесопромышленное», «Русско-Азиатское», «Бр. Грейсер», а также торговые дома: «С.Е. Шишкин и $\mathrm{K}^{\circ} »$, «Лушникова наследники», «Вульф», «Братья Полутовых», «Помус и $\mathrm{K}^{\circ} »$ и др. ${ }^{14}$ В Иркутское отделение Сибирского торгового банка обращались не только местные, но и иногородние предприниматели, в числе которых: красноярский скотопромышленник Капулин Ш.П., Кожевников (с. Полотняный Завод, Калужская губ.), Мокржицкий (Могилевская губ.), Сендарович (с. Кабанск), Новомейский (г. Баргузин) и Шенфиль (г. Верхнеудинск, Забайкальская обл.),

${ }^{13}$ ГАИО. Ф. 155. Оп. 1. Д. 17. Л. 90-91.

${ }^{14}$ Там же. Д. 11. Л. 29, 60, 84, 133, 160, 165, 168, 171. 
Манусович (Томская обл.), Круглихин (г. Ново-Николаевск), Андреев (г. Челябинск), Голых (г. Енисейск), Торговый дом «Бр. С. и Х. Славины в Одессе» и др. ${ }^{15}$ Среди заявителей были и иностранные граждане: Бансвур (г. Вильна), Мовшович (г. Варшава), Литвин (г. Лодзь), Райхштейн (Лаузи, Германия ${ }^{16}$.

В случае одобрения кредита, на заявлении делалась соответствующая отметка с указанием одобренной отделением банка суммы. По всей видимости, в отделении банка не существовало жестких нормативов по определению четких рамок одобряемых кредитов. Это можно объяснить тем, что в начале XX в. поток клиентов был не столь велик, как в наши дни, не существовало общих баз данных, позволяющих моментально проверить кредитную историю; не последнюю роль при одобрении кредита играло и такое понятие как «деловая репутация» и даже «нравственное положение клиента» ${ }^{17}$. Именно поэтому, в определенной степени, при открытии кредита был распространен индивидуальный подход к заявителям. Об отсутствии четко регламентированных кредитных лимитов говорят цифры одобренных займов, не вполне коррелирующие с размерами годовых оборотов заемщиков. Так, например, с одной стороны, размер кредита, одобренный в размере 3 тыс. р. встречается как среди заемщиков с денежным оборотом 20 тыс. р. в год, так и среди заемщиков, имеющих годовой оборот от 500 тыс. до 1 млн р С другой стороны, размер кредита в 25 тыс. р. встречается среди клиентов с годовым оборотом в 200 тыс. р. и в 400 тыс. р., в то время как для клиентов с оборотом в 300 тыс. р. размеры кредитов составляли от 5 до 10 тыс. р. Хотя, в общем и целом зависимость размера одобренного займа от предпринимательского оборота

${ }^{15}$ ГАИО. Ф. 155. Оп. 1. Д. 11. Л. 3, 27, 28, 32, 33, 65, 73, 80, 154, $164,180$.

${ }^{16}$ Там же. Л. 9, 36, 54, 87.

${ }^{17}$ Там же. Д. 17. Л. 76-77. 
все же прослеживается, размытые кредитные рамки для разных категорий заемщиков говорят о присутствии ярко выраженного индивидуального подхода в отношении клиентов банковского отделения [9].

Банк следил, чтобы при частичном выкупе заложенного товара и выдаче его клиенту, остаток залога в банке соответствовал первоначальному его качеству и не происходил отбор лучших единиц залога. Для этого при выдаче товара обязательно должен был присутствовать банковский эксперт ${ }^{18}$.

Правление банка уделяло особое внимание районному кредитованию и недопустимости привлечения заемщиков из других областей страны. По этому поводу отделениям рассылались многочисленные директивы. Правление считало вполне исчерпывающим кредитование отделениями местного предпринимательского сообщества. При этом даже обслуживание своего района местным отделением руководство банка считало непростым делом. Правление не хотело сосредоточивать все риски в одном из своих представительств и поэтому было против того, чтобы даже наиболее выгодные клиенты аккумулировали свои займы в каком-либо одном из местных отделений Сибирского торгового банка. Предпочтительной для правления была ситуация, когда риски, связанные с несостоятельностью заемщика, распределялись в нескольких местных банках ${ }^{19}$.

Правление Сибирского торгового банка было категорически против привлечения отделениями клиентов из других районов. Опираясь на практику ведения дел оно полагало, что желание иногороднего клиента получить кредит кроме своего района еще и в чужом всегда основано на каком-нибудь злом умысле: либо клиент находится на грани банкротства, либо векселя в его портфеле сомнительного качества, в силу

${ }^{18}$ ГАИО. Ф. 155. Оп. 1. Д. 17. Л. 29.

19 Там же. Л. 76 об. 
чего местные банки отказывают ему в кредитовании. Особенно насторожено банк относился к фирмам, имеющим свои отделения в нескольких городах, полагая, что такие фирмы, в силу разбросанности своей деятельности могли особенно легко симулировать качество векселей, выдавая финансовых векселедателей за торговых. Исключения для иногородних клиентов в некоторых случаях все же допускались, однако правление требовало, чтобы все векселя, принимаемые под учет, были из района действия отделения и векселедатели были лично известны руководству отделения как с имущественной, так и с нравственной стороны ${ }^{20}$.

Характерным для правления Сибирского торгового банка было недоверие к учетным комитетам отделений. Так как в этот орган входили как правило видные дельцы из местных предпринимательских кругов, правление небезосновательно считало их людьмы занятыми, имеющими свои интересы помимо работы в учетном комитете банковского отделения. В силу чего, на взгляд правления, члены комитета относятся к своей работе в банке как к занятию «побочному», а их «нравственная ответственность сводится обыкновенно к нулю». Помимо всего прочего банковское руководство подозревало возможность сговора членов учетного комитета с некоторыми предпринимателями, чьи интересы они лоббировали в своей деятельности ${ }^{21}$. Если такие случаи и имели место в практике работы отделений банка, то они, безусловно, являлись формой коррупции в частном секторе дореволюционной России.

Правление банка внимательно следило за конъюнктурой рынка. Так, в июне 1908 г. оно запрашивало в отделениях банка информацию по спросу на сахар в регионах, чтобы принять решение о комиссионной продаже продукции сахарного завода Янушпольского

${ }^{20}$ ГАИО. Ф. 155. Оп. 1. Д. 17. Л. 77.

${ }^{21}$ Там же. 
Т-ва через свои отделения ${ }^{22}$. В октябре 1908 г. правление Сибирского торгового банка разослало своим сибирским отделениям циркуляры с предостережением о выдаче ссуд под залог зерна. Последнее обстоятельство было вызвано плохим урожаем зерновых в Сибири в отличие от южных областей страны, где урожай оказался хорошим ${ }^{23}$.

Руководству Сибирского торгового банка была не чужда социальная политика в отношении своих служащих. В случае смерти сотрудника практика организованной взаимопомощи наряду с мерами поддержки семей со стороны самого банка охватывала всех работников его многочисленных отделений. По случаю смерти любого сотрудника банка на территории страны его родным выдавалось посмертное пособие. Причем последнее делилось на две части: одна треть пособия выплачивалась непосредственно банком, две трети - вычитались из заработной платы служащих всех банковских отделений. Размер пособия зависел от должности умершего: в случае смерти управляющего вычет из заработной платы служащих составлял 2000 р., бухгалтера, доверенного - 1333,34 р., артельщика, приказчика и другого рядового служащего - 666,67 p. ${ }^{24}$

Oсобое значение в отдлениях банка уделялось мерам по борьбе с мошенничеством. Периодически банку приходилось сталкиваться со случаями выдачи денежных средств по подложным чекам, фиктивным квитанциям, фальшивым платежным телеграммам и уведомлениям из других отделений, изредка встречались случаи ограбления касс.

Банк направлял все средства на расследование происшествий, принесших ему убыток, и в случае установления виновности одного из своих сотрудников возлагал на него всю материальную ответственность

${ }^{22}$ ГАИО. Ф. 155. Оп. 1. Д. 17. Л. 34.

${ }^{23}$ Там же. Л. 4.

${ }^{24}$ Там же. Д. 19. Л. 10, 76. 
за случившиеся. Для предотвращения мошеннических действий банком предпринимались различные меры: шифрование внутренней корреспонденции, проставление дополнительных печатей на документации. Пристальное внимание уделялось хранению ключей от кладовых и несгораемых шкафов, в которых размещались ценности.

Отдельно всякий раз руководство банка заостряло внимание на работе отделений с неизвестными, малоизвестными или недостаточно зарекомендовавшими себя фирмами и лицами, обслуживание которых считалось в крайней степени нежелательным. В этом случае нежелательными признавались не только активные операции банка, такие как учет векселей или ссудная деятельность, но и пассивные операции, к которым относилась, в частности, операция приема вкладов. Таким образом, руководство банка настолько опасалось злоупотреблений со стороны малоизвестных лиц, что рекомендовало своим отделениям воздерживаться даже от приема денежных средств от них, объясняя это возможностью существования у таких вкладчиков скрытого умысла.

Таким образом, политика банковского правления в отношении своих отделений отличалась прагматизмом и осторожностью. Банк предпочитал отказаться от дополнительной прибыли в интересах снижения рискованности своих операций. С этой целью он руководствовался принципом районного кредитования, сдержанно относился к мнению членов учетных комитетов, проводил осторожную политику в отношении вексельных займов. При этом руководство банка чутко следило за экономической ситуацией в регионах, осуществляло постоянный анализ и мониторинг рыночной конъюнктуры. Правление банка проводило продуманную кадровую политику, занимаясь стратегической подготовкой сотрудников для замещения руководящих должностей. Не чужда руководству бан- 
ка была и социальная политика в отношении своих сотрудников, свидетельством чего является в отдельных случаях бесплатное предоставление жилья, выдача квартирных пособий, а также денежных средств семьям умерших служащих.

Период конца 1917 - первой половины 1918 гг. стал периодом турбулентности для иркутского отделения Сибирского торгового банка. После революционных событий, потрясших г. Иркутск в декабре 1917 г., и прокатившейся по Иркутской губернии волне первой национализации, отделение возобновило свою деятельность после отступления большевиков из региона в июле 1918 г. Однако деятельность его продолжалась недолго, ровно через полтора года регион потрясла новая смена политического режима, принесшая окончательную национализацию банковской сферы - банковское дело было объявлено государственной монополией.

\section{Список использованной литературы}

1. Гиндин И.Ф. Русские коммерческие банки : Из истории финансового капитала в России / И.Ф. Гиндин ; под ред. С.Г. Струмилина. - Москва : Госфиниздат, 1948. - 454 с.

2. Рабинович Г.Х. Крупная буржуазия и монополистический капитал в экономике Сибири конца XIX - начала XX вв. / Г.Х. Рабинович. - Томск : Изд-во Том. ун-та, 1975. $328 \mathrm{c}$.

3. Ананьич Б.В. Банкирские дома в России, 1860-1914 гг. Очерки истории частного предпринимательства / Б.В. Ананьич. - Ленинград : Наука, 1991. - 196 с.

4. Бовыкин В.И. Коммерческие банки Российской империи / В.И. Бовыкин, Ю.А. Петров. - Москва : Перспектива, 1994. - 350 c.

5. Саломатина С.А. Коммерческие банки в России: динамика и структура операций, 1864-1917 гг. / С.А. Саломатина. - Москва : РОССПЭН, 2004. - 302 с.

6. Шахеров В.П. Государственный банк в г. Иркутске: от Российской империи до настоящего времени : К 150-летию со дня основания / В.П. Шахеров, Н.И. Гаврилова. - Иркутск : Оттиск, 2019. - 372 с. 
7. Гаврилова Н.И. Социальный состав учетно-ссудного комитета Иркутского отделения Государственного банка в конце XIX - начале XX вв. / Н.И. Гаврилова / / Общество: философия, история, культура. - 2020. - № 8 (76). - С. 65-69.

8. Гаврилова Н.И. Служащие сибирских региональных отделений Государственного банка второй половины XIX начала XX в.: динамика социального состава (по материалам Иркутского отделения Госбанка) / Н.И. Гаврилова // Известия Иркутского государственного университета. Серия: История. - 2018. - Т. 26. - С. 52-61.

9. Плотникова Е.В. Заемщики Иркутского отделения Сибирского торгового банка в 1904-1907 гг. / Е.В. Плотникова // Гуманитарные науки в Сибири. - 2020. - Т. 27, № 2. - С. 54-61.

\section{References}

1. Gindin I.F.; Strumilin S.G. (ed.). Russkie kommercheskie ban$k i$ : Iz istorii finansovogo kapitala v Rossii [Russian Merchant Banks: on History of Financial Capital in Russia]. Moscow, Gosfinizdat Publ., 1948. 454 p.

2. Ananich B.V. Bankirskie doma v Rossii. 1860-1914 gg. Ocher$k i$ istorii chastnogo predprinimatel'stva [Banking houses in Russia. 1860-1914. Essays on the history of private enterprise]. Leningrad, Nauka Publ., 1991. 196 p.

3. Salomatina S.A. Kommercheskie banki v Rossii : dinamika $i$ struktura operatsii, 1864-1917 gg. [Commercial Banks in Russia: the Dynamics and Structuring of Operations, 1864-1917]. Moscow, ROSPEN Publ., 2004. 302 p.

4. Bovykin V.I., Petrov Yu.A. Kommercheskie banki rossiiskoi imperii [Commercial Banks of the Russian Empire]. Moscow, Perspektiva Publ., 1994. 350 p.

5. Rabinovich G.Kh. Krupnaya burzhuaziya i monopolisticheskii kapital v ekonomike Sibiri kontsa XIX - nachala XX vv. [The Upper Middle Class and Monopoly Capital in Siberian Economy in the late $19^{\text {th }}$ and the early $20^{\text {th }}$ centuries.]. Tomsk State University Publ., 1975. 328 p.

6. Shakherov V.P., Gavrilova N.I. Gosudarstvennyi bank v g. Irkutske: ot Rossiiskoi imperii do nastoyashchego vremeni [The State Bank in Irkutsk: from the Russian Empire to the present day]. Irkutsk, Ottisk Publ., 2019. 372 p.

7. Gavrilova N.I. Accounting and Loan Committee Social Composition $\mathrm{N}$ the Irkutsk Branch of the State Bank in the Late XIX Early XX Centuries. Obshchestoo: filosofiya, istoriya, kul' tura = Society: Philosophy, History, Culture, 2020, no. 8 (76), pp. 65-69. (In Russian). 
8. Gavrilova N.I. Employees of the Siberian Regional Branches of the National Bank of the Second Half of the XIX - Early XX Century: Dynamics of Social Composition (Based on the Irkutsk Branch of the State Bank). Izvestiya Irkutskogo gosudarstvennogo universiteta. Seriya: Istoriya $=$ The Bulletin of Irkutsk State University. Series: History, 2018, vol. 26, pp. 52-61. (In Russian).

9. Plotnikova E.V. Borrowers of the Irkutsk Branch of the Siberian Commercial Bank in 1904-1907. Gumanitarnye nauki $v$ Sibiri $=$ Humanitarian sciences in Siberia, 2020, vol. 27, no. 2, pp. 54-61. (In Russian).

\section{Инфрормация об авторе}

Плотникова Елена Владиславовна - аспирант, кафедра истории России, Иркутский государственный университет, г. Иркутск, Российская Федерация, e-mail: Elenaangarsk@yandex.ru. ORCID ID: 0000-0002-3171-7261.

\section{Author}

Elena V. Plotnikova - Postgraduate, Department of History of Russia, Irkutsk State University, Irkutsk, the Russian Federation, e-mail: Elena-angarsk@yandex.ru. ORCID ID: 00000002-3171-7261.

\section{Для цитирования}

Плотникова Е.В. Политика правления Сибирского торгового банка в отношении региональных подразделений: случай Иркутского отделения, 1873-1920 гг. / E.В. Плотникова. - DOI: 10.17150/2308-2488.2021.22(1).121139 / / Историко-экономические исследования. - 2021. T. 22, № 1. - C. 121-139.

\section{For Citation}

Plotnikova E.V. The Policy of Management Board at Siberian Merchant Bank toward Regional Branches: the Case of the Irkutsk branch between 1873 and 1920. Istoriko-ekonomicheskie issledovaniya $=$ Journal of Economic History $\mathcal{E}$ History of Economics, 2021, vol. 22, no. 1, pp. 121-139. DOI: 10.17150/23082488.2021.22(1).121-139. (In Russian). 